\title{
Palinotaxonomia de Passiflora L. subg. Decaloba (DC.) Rchb. (Passifloraceae) no Brasil ${ }^{1}$
}

\author{
Michaele Alvim Milward-de-Azevedo ${ }^{2,3,5}$, Fabiana Carvalho de Souza ${ }^{3}$, \\ José Fernando Andrade Baumgratz ${ }^{2,4}$ e Vania Gonçalves-Esteves ${ }^{2,3}$
}

Recebido em 25/03/2009. Aceito em 2/06/2009

RESUMO - (Palinotaxonomia de Passiflora L. subg. Decaloba (DC.) Rchb. (Passifloraceae) no Brasil). Foram tratados, palinologicamente, 21 táxons de Passiflora L. subg. Decaloba (DC.) Rchb. (Passifloraceae) ocorrentes no Brasil, com o objetivo de contribuir para a caracterização, circunscrição e delimitação do subgênero, espécies e subespécie. Os grãos de pólen foram acetolisados, medidos, descritos e ilustrados sob microscopia de luz. Grãos de pólen não acetolisados foram usados na microscopia eletrônica de varredura. Os táxons possuem grãos de pólen grandes ou médios, isopolares, prolato-esferoidais, oblato-esferoidais, esferoidais ou subprolatos, 12-colpados, 12-colporados ou 6-colporados, 3 ou 6 mesocolpos, e presença ou ausência de opérculos, pseudopérculos e opérculos secundários, exina microrreticulada em $P$. truncata e heterorreticulada nas demais espécies. Foi confeccionada uma chave para a identificação das espécies com base nos dados polínicos, mostrando que características polínicas têm grande importância na taxonomia de Passiflora. Palavras-chave: Passiflora subg. Decaloba; palinologia; taxonomia; Brasil

ABSTRACT - (Palynotaxonomy of Passiflora L. subg. Decaloba (DC.) Rchb. (Passifloraceae) in Brazil). The palynological study of 21 taxa of Passiflora L. subg. Decaloba (DC.) Rchb. (Passifloraceae) in Brazil aimed to contribute to a better characterization, as well as the circumscription and delimitation of the subgenus, species and subspecies. The pollen grains were acetolysed, measured, described and illustrated using light microscopy and scanning electron microscopy. The taxa have large or medium-sized pollen grains, isopolar, prolate spheroidal, oblate spheroidal, spheroidal or suprolate, 12-colpate, 12-colporate or 6-colporate, 3 or 6 mesocolpes, and presence or absence of opercules, pseudopercules and secondary opercules, microreticulate $(P$. truncata) and heteroreticulate exine in the other species. An identification key with pollen characteristics is presented, showing the importance of pollen characteristics for Passiflora taxonomy.

Key words: Passiflora subg. Decaloba; palynology; taxonomy; Brazil

\section{Introdução}

Passiflora (Passifloraceae), encontra-se dividida em quatro subgêneros, dentre eles Decaloba (DC.) Rchb., que apresenta distribuição tropical e subtropical, com cerca de 235 espécies, subdivididas em oito superseções (Ulmer \& MacDougal 2004). No Brasil, o subgênero apresenta um total de 20 espécies e uma subespécie, incluindo trepadeiras herbáceas, com estípulas linear-subuladas ou falcadas, às vezes foliáceas, presença ou ausência de oceolos nas lâminas foliares, flores pequenas ( $4 \mathrm{~cm}$ diâm.), com uma ou duas séries de filamentos da corona e opérculo plicado, grãos de pólen médios a grandes reticulados, frutos bacóides ou cápsulas e sementes reticuladas, foveoladas ou transversalmente sulcadas (Milward-de-Azevedo, dados não publicados).

Estudos palinológicos em espécies de Passifloraceae iniciaram com Presting (1965), que apresentou uma análise minuciosa do sistema apertural, propondo uma filogenia para a família baseada em características polínicas e na classificação de Killip (1938). O autor considerou que o desenvolvimento das aberturas dos pólens nessa família evoluiu segundo três ramos e que a forma primitiva ou basal consistia em grãos de pólen simples, 3-colporados ou, às vezes, 4-colporados, com colpos longos e estreitos, muros simpli ou duplicolumelados, às vezes ambos, raramente multicolumelados. As espécies foram agrupadas, morfologicamente, em subgêneros, seções e séries, seguindo a classificação de Killip (1938) e de acordo com a presença de opérculo secundário.

Dentre as espécies do subgênero Decaloba ocorrentes no Brasil, foram analisadas $P$. auriculata Kunth, P. capsularis L., P. misera Kunth, P. morifolia Mast., P. organensis Gardn., P. pohlii Mast. e P. suberosa L. Spirlet (1965) associou a sistemática usual do gênero Passiflora com a morfologia dos grãos de pólen, mostrando que essa classificação segue as propostas evolutivas que têm sido apresentadas sobre as Passifloraceae. Por sua vez, Huynh (1972) estudou o arranjo dos micrósporos no estágio de tétrade pós-meiótico de P. capsularis e P. suberosa, entre outras, mostrando que o gênero Passiflora pode apresentar num mesmo grão de pólen mesocolpos de diferentes dimensões. Garcia et al. (2002) estudaram a fase de microesporângio, microgametose e a morfologia do pólen de seis espécies de Passiflora pertencentes a três subgêneros, entre eles Decaloba, com as espécies $P$. misera e $P$. suberosa. Milward-de-Azevedo et al. (2004) apresentaram um estudo palinotaxonômico de oito espécies de Decaloba ocorrentes na Região Sudeste do Brasil, contribuindo para sua caracterização, circunscrição e delimitação. Araújo \& Santos (2004) apresentaram a descrição da morfologia polínica das espécies de Passiflora ocorrentes na Chapada Diamantina, Bahia, incluindo P. misera e $P$. suberosa. Barrios et al. (2005) fizeram a caracterização dos pólens de espécies do gênero Passiflora.

\footnotetext{
Parte da Tese de Doutorado da primeira Autora

2 Universidade Federal do Rio de Janeiro, Programa de Pós-graduação em Ciências Biológicas (Botânica), Rio de Janeiro, RJ, Brasil

3 Universidade Federal do Rio de Janeiro, Museu Nacional, Departamento de Botânica, Rio de Janeiro, RJ, Brasil

4 Instituto de Pesquisas Jardim Botânico do Rio de Janeiro, Rio de Janeiro, RJ, Brasil

5 Autor para correspondência: michaele@jbrj.gov.br
} 
O presente estudo visa à caracterização polínica dos táxons de Passiflora subg. Decaloba ocorrentes no Brasil, com o objetivo de também auxiliar à taxonomia e filogenia do grupo.

\section{Material e métodos}

O material polínico foi obtido de botões florais de exemplares depositados nos seguintes herbários: EAC, ESAL, HAS, HRB, HUEFS, IAC, IBGE, ICN, MBML, PACA, PEUFR, R, RB, RBR, SP, SPF, UB, VIC e UPCB (siglas de acordo com Holmgren et al. 1990), utilizando-se material coletado em diversas regiões do Brasil.

O material considerado como padrão é indicado por asterisco junto à sigla do herbário depositário e, os outros, como comparação. Relação do material estudado: Passiflora amalocarpa Barb. Rodr. - Amazonas: Barcelos, 24/X/1952, R.L. Fróes 29041 (IAN); Manaus, 26/VI/1979, J.M. Poole 1627 (RB*); Acre: Rio Branco, V/1913, J. G. Kuhlmann s.n. (RB 3413). P. auriculata Kunth - AMAZONAS: Itacoatiara, 12/III/2003, E.A. Anunciação et al. 853 (SP); Manaus, 8/IV/1943, A.P. Duarte 1213 (RB); São Gabriel da Cachoeira, 18/IV/1947, J.M. Pires 395 (RB); Mato Grosso: Arroz sem Sal, IV/1918, J.G. Kuhlmann 2189 (R, RB*). P. candollei Barb. Rodr. - Acre: Acrelândia, 13/II/2000, I.S. Ribeiro s.n. et al. (UPCB 52342*); Amazonas: Benjamim Constant, 9/IX/1962, A.P. Duarte 7289 (RB); Manaus, II/1937, A. Ducke s.n. (RB 34969); Purús, 3/XII/1923, J.G. Kuhlmann 922 (RB). P. capsularis L. - Pará: Conceição do Araguaia, $7 /$ XII/1969, L. Baptista s.n. (ICN 7229*); Paraná: Cerro Azul, sem data, G. Hatschbach 47634 (HRB); Santa Catarina: Chapecó, 30/XII/1963, Reitz et Klein 16649 (RB); Rio Grande do Sul, Marcelino Ramos, 25/III/1987, O. Bueno 4963 (HAS). P. cervii Milward-de-Azevedo - Minas Gerais: Paraopeba, 10X/1958, E.P. Heringer 6578 (UB); PARANÁ: Rio Branco do Sul, 25/XI/1982, P.I. Oliveira 691 (SP); Rio Grande do Sul: Barra do Ouro, 23/III/2002, A.P. Lorenz s.n. (ICN 125483*); Montenegro, 21/I/1947, A. Sehnem 2430 (PACA). P. glaucescens Killip - Espírito Santo: Santa Leopoldina, 14/IX/2006, R. Marquete et al. 3919 (RB*); São Paulo: São Paulo, 22/III/1935, Kraenzlin et Schlechter s.n. (IAC 37655, SP 32575). P. jiboiaensis Milward-de-Azevedo - Bahia: Santa Terezinha, 19/X/2000, J.G. Carvalho-Sobrinho et al. 40 (HUEFS*); P. longilobis Hoehne-Tocantins: Piuim, 27/III/1999, M.A. Silva et al. 4179 (IBGE*); Mato Grosso do Sul: Bataguassú, 20/XI/1992, I. Cordeiro et al. 976 (SP). P. misera Kunth Rio de Janeiro: São João da Barra, 18/IX/2003, M.C. Gaglianone et al. 104 (RB*); São Paulo: Campinas, 6/XI/1938, C. Franco et P. Mendes s.n. (IAC 2851). P. morifolia Mast. - São Paulo: São Paulo, 21/III/1945, W. Hoehne s.n. (IAC 32621, SPF 11470); Paraná: Ibaiti, 4/II/1988, W.M. Kranz 183 (UPCB*); Londrina, F. Chagas e Silva 1271 (UPCB). P. organensis Gardn. - Espirito Santo: Santa Teresa, 15/II/2003, R.R Vervloet et A.P. Fontana 1836 (MBML*); Domingos Martins, 19/I/1975, A.L. Peixoto et al. 480 (RBR); Minas Gerais: Realeza, 18/I/1985, A. Gentry et al. 49692 (RBR); São Tomé das Letras, 20/II/1991, M.L. Gavillanes et F. Frieiro 4850 (ESAL*); Rio de Janeiro: Rio de Janeiro, 28/VII/1958, E. Pereira et al. 4056 (RB); Santa Maria Madalena, 21/III/1989, R. Marquete et al. 211 (RB); São Paulo: Guapiara, II/1913, s. col. (RB 1617); Santa Catarina: Praia Grande, 10/I/1987, D.B. Falkenberg et al. 4143 (PACA); Rio Grande do Sul: Morrinhos do Sul, 29/I/1993, J.A. Jarenkow et D.B. Falkenberg 2298 (ICN). P. pardifolia Vanderplank - Maranhão: sem data, s. col. (RB 412311*). P. pohlii Mast. - Goiás: Caldas Novas, 4/IX/1982, E.P. Heringer 18528 (IBGE); Niquelândia, 17/IX/1996, M.A. Silva et al. 3074 (RB*); ibidem, 30/IX/1997, M.L. Fonseca et al. 1567 (RB); Minas Gerais: sem localidade, 1862, H.S. Irwin et T.R. Soderstrom 5559 (UB); Lavras, 26/X/1985, F. Frieiro-Costa s.n. (ESAL 4663); Montes Claros, 6/X/1978, M.P. Coons 78-1131 (VIC); Paraopeba, 10/X/1954, E.P. Heringer 3589 (UB); ibidem, 15/II/1958, E.P. Heringer 6579 (UB). P. rubra L. - Ceará: Maranguape, 23/I/1968, Z. Trinta et al. 1270 (PACA, R*); Pacatuba, 11/ XI/1983, A. Fernandes s.n. (EAC 12237); Pernambuco: Maraial, 19/ IV/1994, A.M. Miranda et L.P. Félix 1527 (PEUFR). P. saxicola Gontsch. - Goiás: São João da Aliança, 30/XII/1979, F. Chagas e Silva et R.C. Mendonça 151 (IBGE); Bahia: Itacaré, 31/III/1974, R.M. Harley 17540 (RB*). P. suberosa subsp. litoralis Kunth - Rio de Janeiro: Niterói, 9/ IX/1992, P. Avellar s.n. (RUSU 3290*); Rio Grande do Sul: Santo Amaro do Sul, 26/XI/1997, J. Larocca s.n. (HASU 10207, PACA 91586). P. transversalis Milward-de-Azevedo - Paraná: Balsa Nova, 16/I/1904, $P$.
Dúsen 3085 (R); Santa Catarina: Mondaí, 2/I/1957, L.B. Smith et R. Reitz s.n. (R 198814); Rio Grande do Sul: Pântano Grande, 30/I/1984, M.L. Abruzzi 877 (HAS); São Jerônimo, 15/XII/1982, T.S. Strehl 512 (HAS*); São Pedro do Sul, 13/I/1984, O. Bueno 3788 (HAS). P. tricuspis Mast. - Mato Grosso do Sul: Campestre, 27/I/2001, M. Groppo Jr. et al. 578 (SPF); Minas Gerais: Pitangui, 1/V/2001, F.C. Campos Neto s.n. (BHCB 64897); São Paulo: Magda, 30/XI/1994, L.C. Bernacci et al. 841 (IAC*, SPF, UEC). P. truncata Regel - Rio de Janeiro: Mendes, 6/III/1980, M.B. Cosori et al. 166 (GUA); Rio de Janeiro, 22/I/1932, Brade s.n. (R 90277); Paraná: Volta Grande, 19/X/1983, A.C. Cervi 2191 (UPCB*). P. urnifolia Rusby-Paraná: Faxinal, 16/XI/1969, G. Hatschbach 22883 (HRB*, HUM, UEC, S). P. vespertilio L. - Pará: Oriximiná, 17/VI/1980, G. Martinelli et al. 7000 (RB); ibidem, 17/VI/1980, C. Davidson et G. Martinelli 10317 (UB*); Amapá: Oiapoque, 1/II/1950, R.L. Fróes 25791 (IAC).

Os grãos de pólen acetolisados (Erdtman 1960) foram analisados sob microscopia de luz, sendo mensurados até sete dias após sua preparação (Salgado-Labouriau 1973), descritos e fotomicrografados. Para a análise sob microscopia eletrônica de varredura, o material polínico não acetolisado foi colocado sobre suportes específicos e metalizados (ca. três minutos) em ouro puro e eletromicrografados em microscópio Zeiss DSM960, no laboratório de Biofísica da UFRJ.

Nas amostras-padrão mediu-se o diâmetro polar (DP) e o diâmetro equatorial (DE) de 25 grãos de pólen em vista equatorial, calculando-se a média aritmética $(\mathrm{x})$, o desvio padrão da média (s), o coeficiente de variabilidade (CV\%) e o intervalo de confiança a $95 \%$.

Foram realizadas, para cada táxon na amostra-padrão, dez medidas da abertura (comprimento e largura) em vista equatorial, bem como da exina (sexina e nexina), do diâmetro do lúmen, do diâmetro equatorial (DEVP) e do lado do apocolpo (LA) em vista polar. A medida da exina foi feita sempre com o pólen em vista polar, na região mediana do mesocolpo. Nestes casos, foi apenas calculada a média aritmética. A terminologia adotada segue Punt et al. (2007).

Para os espécimes de comparação foram realizadas dez medidas do diâmetro polar (DP) e do diâmetro equatorial (DE) em vista equatorial, calculando-se a média aritmética.

O termo pseudopérculo foi usado neste estudo para descrever o opérculo situado entre duas aberturas contíguas, conforme proposto por Presting (1965) e aceito por Milward-de-Azevedo et al. (2004). Já o termo opérculo secundário foi adotado para descrever o opérculo situado entre o mesocolpo e o pseudopérculo, conforme proposto por Presting (1965).

\section{Resultados}

Os táxons de Passiflora subg. Decaloba (Fig. 1-105) possuem grãos de pólen médios a grandes, isopolares, oblato-esferoidais ( $P$. cervii), subprolatos ( $P$. auriculata, P. candollei, P. glaucescens, $P$. morifolia, $P$. pardifolia, $P$. pohlii e $P$. suberosa subsp. litoralis) ou prolato-esferoidais (P. amalocarpa, . capsularis, $P$. jiboiaensis, $P$. longilobis, $P$. misera, P. organensis, P. rubra, P. saxicola, P. transversalis, $P$. tricuspis, $P$. truncata, $P$. urnifolia e $P$. vespertilio), com âmbito circular, área polar pequena ( $P$. auriculata, $P$. morifolia, P. organensis, P. pohlii e P. suberosa subsp. litoralis) a muito pequena (Tab. 1-3).

São encontrados grãos de pólen 6-colporados em $P$. auriculata (Fig. 9), P. glaucescens (Fig. 26), P. jiboiaensis (Fig. 31), P. organensis (Fig. 52), P. pohlii (Fig. 64), P. truncata (Fig. 91) e P. urnifolia (Fig. 97), 12-colpados em $P$. capsularis (Fig. 16) e P. suberosa subsp. litoralis (Fig. 76) e 12-colporados em P. amalocarpa (Fig. 1), P. candollei (Fig. 12), P. cervii (Fig. 22), P. longilobis (Fig. 37), P. misera (Fig. 42), P. morifolia (Fig. 47), P. pardifolia (Fig. 56), P. rubra (Fig. 66), P. saxicola (Fig. 72), P. transversalis (Fig. 81), $P$. tricuspis (Fig. 86) e P. vespertilio (Fig. 102). 

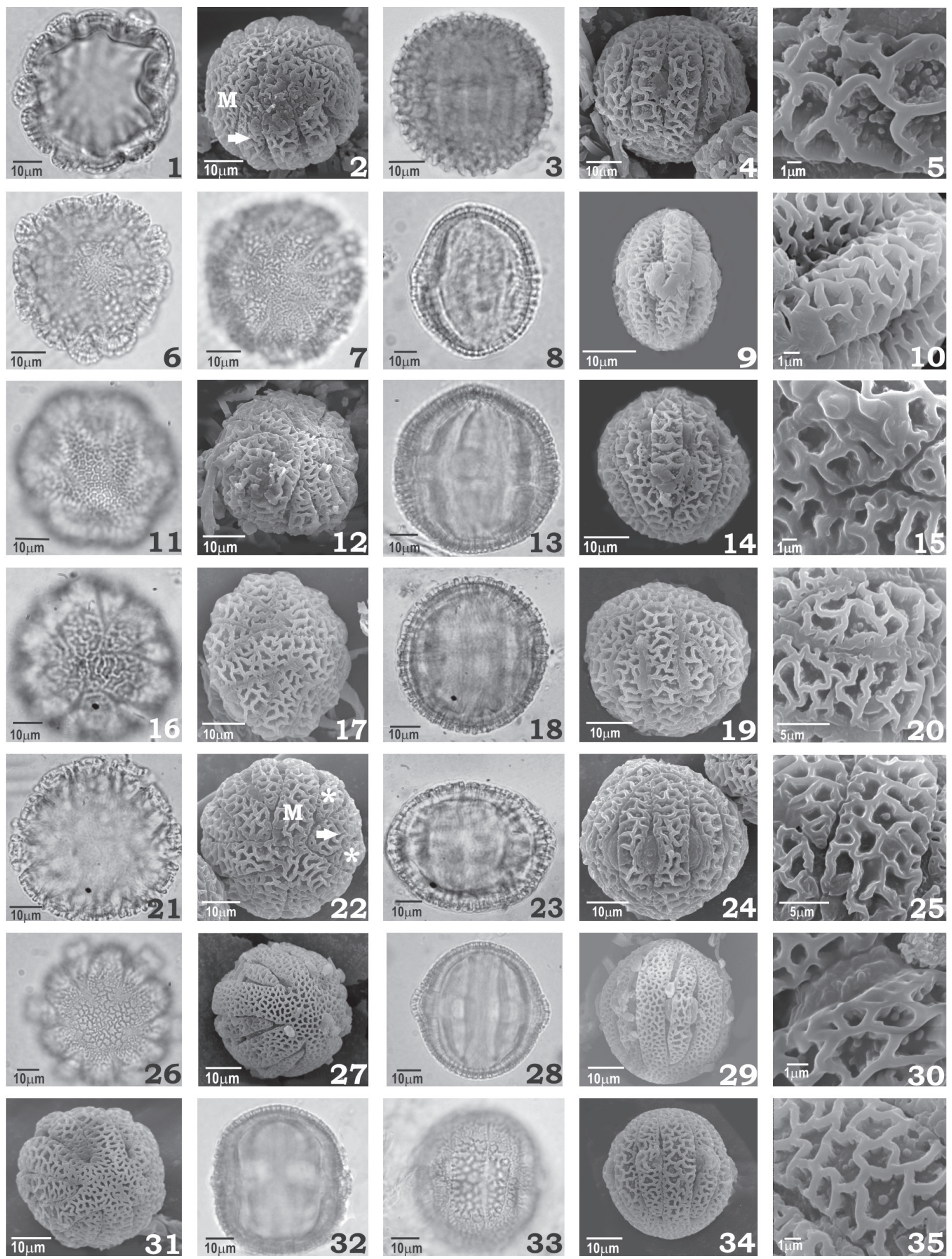

Figura 1-35: Fotomicrografias e eletromicrogafias dos grãos de pólen de espécies de Passiflora subg. Decaloba: P.amalocarpa - vista polar: 1. corte óptico, 2. apocolpo (MEV), vista equatorial: 3. corte óptico, 4. abertura (MEV), 5. detalhe de superfície (MEV); P. auriculata - vista polar: 6 . corte óptico, 7. superfície, vista equatorial: 8. corte óptico, 9. abertura (MEV), 10. detalhe de superfície (MEV); P. candollei - vista polar: 11. aspecto geral e superfície, 12. apocolpo (MEV), vista equatorial: 13. corte óptico, 14. abertura (MEV), 15. detalhe de superfície (MEV); P. capsularis - vista polar: 16. apocolpo e superfície, 17. vista geral (MEV), vista equatorial: 18. corte óptico, 19. abertura (MEV), 20. detalhe de superfície (MEV); P. cervii - vista polar: 21. corte óptico, 22. apocolpo (MEV), vista equatorial: 23. corte óptico, 24. abertura (MEV), 25. detalhe de superfície (MEV); P. glaucensces - vista polar: 26. vista geral, 27. apocolpo (MEV), vista equatorial: 28. corte óptico, 29. abertura (MEV), 30. detalhe de superfície (MEV). P. jiboiaensis - vista polar: 31. apocolpo (MEV), vista equatorial: 32. corte óptico, 33. abertura, 34. abertura (MEV), 35. detalhe de superfície (MEV). A seta representa o pseudoopérculo, o "M", o mesocolpo, o asterisco ( *), o opérculo secundário. 

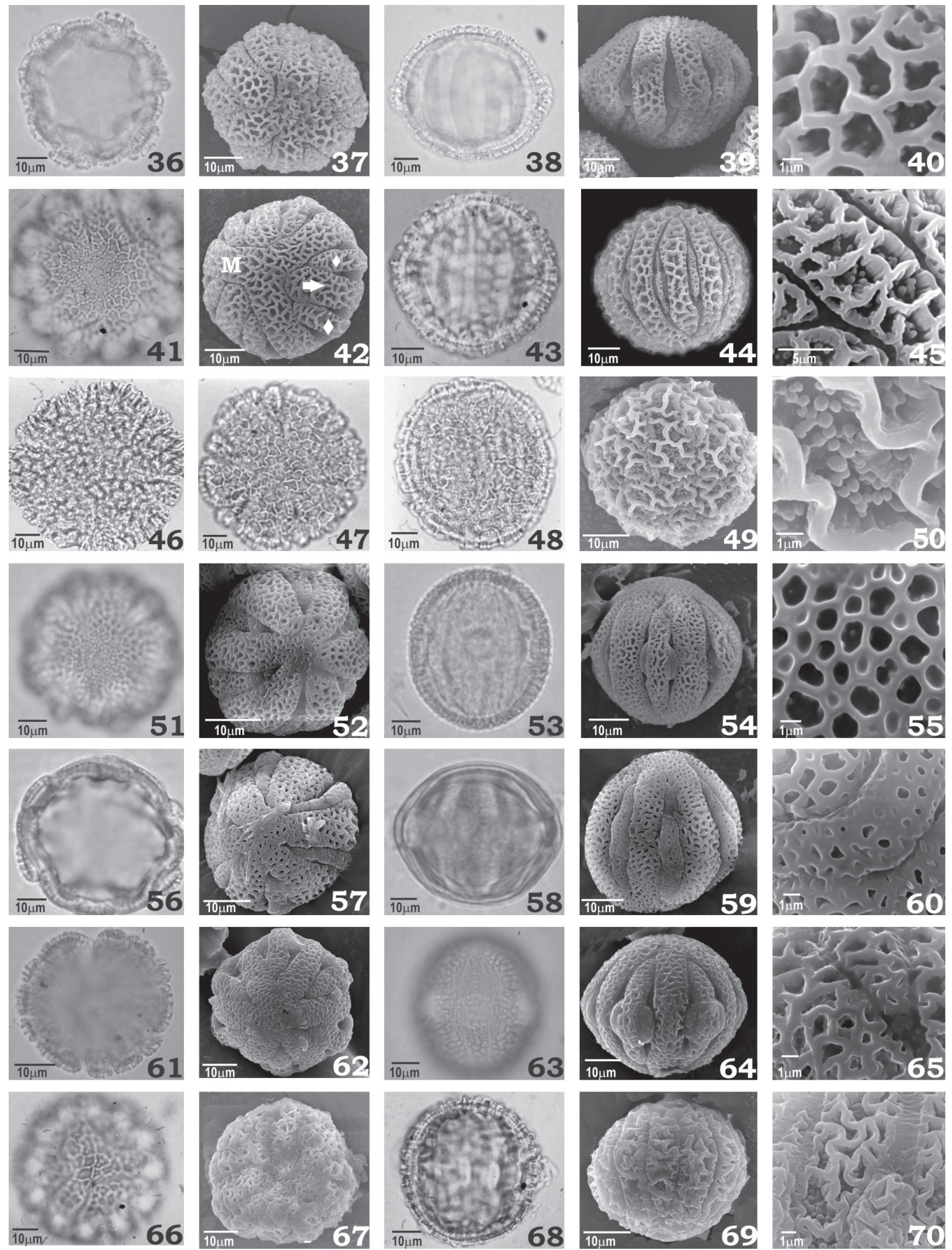

Figura 36-70: Fotomicrografias e eletromicrogafias dos grãos de pólen de espécies de Passiflora subg. Decaloba: P. longilobis - vista polar: 36. corte óptico, 37. apocolpo (MEV), vista equatorial: 38. corte óptico, 39. abertura (MEV), 40. detalhe de superfície (MEV); P. misera - vista polar: 41. apocolpo e superfície, 42. apocolpo (MEV), vista equatorial: 43. corte óptico, 44. abertura (MEV), 45. detalhe de superfície (MEV); P. morifolia - vista polar: 46. corte óptico, 47. apocolpo e superfície, vista equatorial: 48. corte óptico, 49. vista geral (MEV), 50. detalhe de superfície (MEV); P. organensis - vista polar: 51. apocolpo e superfície, 52. apocolpo (MEV), vista equatorial: 53. corte óptico, 54. abertura (MEV), 55. detalhe de superfície (MEV); $P$. pardifolia - vista polar: 56. corte óptico, 57. apocolpo (MEV), vista equatorial: 58. corte óptico, 59. abertura (MEV), 60. detalhe de superfície (MEV); P. pohlii - vista polar: 61. corte óptico, 62. apocolpo (MEV), vista equatorial: 63. abertura, 64. abertura (MEV), 65. detalhe de superfície (MEV); P. rubra - vista polar: 66. análise de L.O., 67. apocolpo (MEV), vista equatorial: 68. corte óptico, 69. abertura (MEV), 70. detalhe de superfície (MEV). A seta (®) representa o pseudoopérculo, o "M", o mesocolpo, o (») losango, o opérculo. 

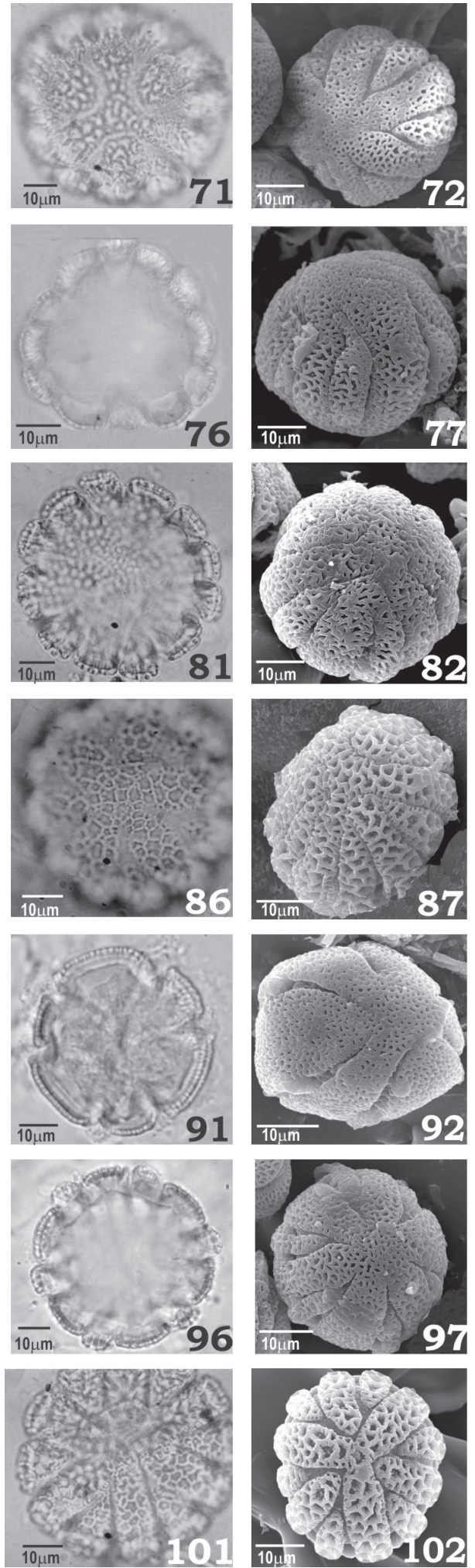
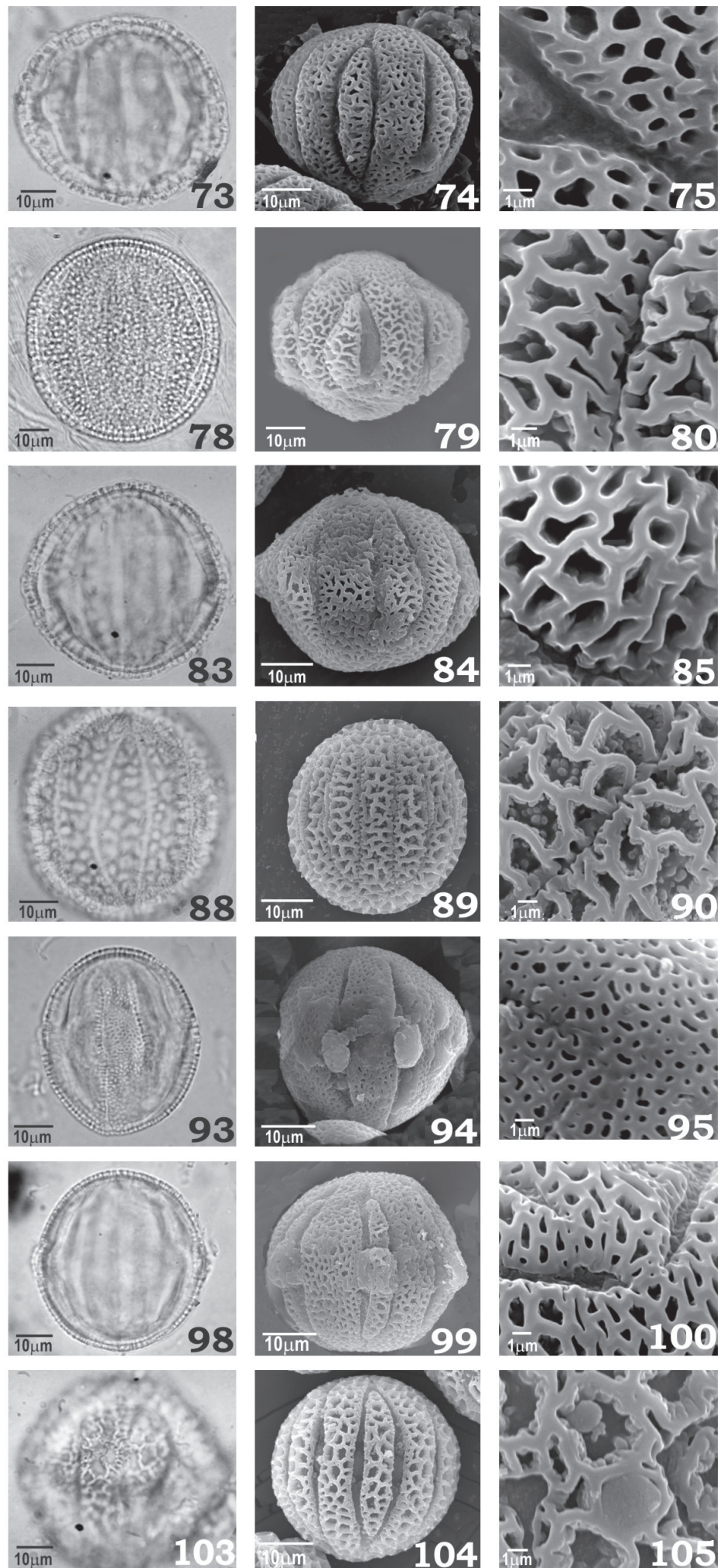

Figura 71-105: Fotomicrografias e eletromicrogafias dos grãos de pólen de espécies de Passiflora subg. Decaloba: P. saxicola - vista polar: 71. vista geral, 72. apocolpo (MEV), vista equatorial: 73. corte óptico, 74. abertura (MEV), 75. detalhe de superfície (MEV); P. suberosa subsp. litoralis - vista polar: 76. corte óptico, 77. apocolpo (MEV), vista equatorial: 78. corte óptico, 79. abertura (MEV), 80. detalhe de superfície (MEV); P. transversalis - vista polar: 81. corte óptico, 82. apocolpo (MEV), vista equatorial: 83. corte óptico, 84. abertura (MEV), 85. detalhe de superfície (MEV); P. tricuspis - vista polar: 86. vista geral, 87. apocolpo (MEV), vista equatorial: 88. abertura, 89. abertura (MEV), 90. detalhe de superfície (MEV); $P$. truncata - vista polar: 91 corte óptico, 92. apocolpo (MEV); vista equatorial: 93. corte óptico, 94. abertura (MEV), 95. detalhe de superfície (MEV); P. urnifolia - vista polar: 96. corte óptico, 97. apocolpo (MEV), vista equatorial: 98 corte óptico, 99. abertura (MEV), 100. detalhe de superfície (MEV); P. vespertilio - vista polar: 101. apocolpo e superfície, 102. apocolpo (MEV), vista equatorial: 103. abertura, 104. abertura (MEV), 105. detalhe de superfície (MEV). 


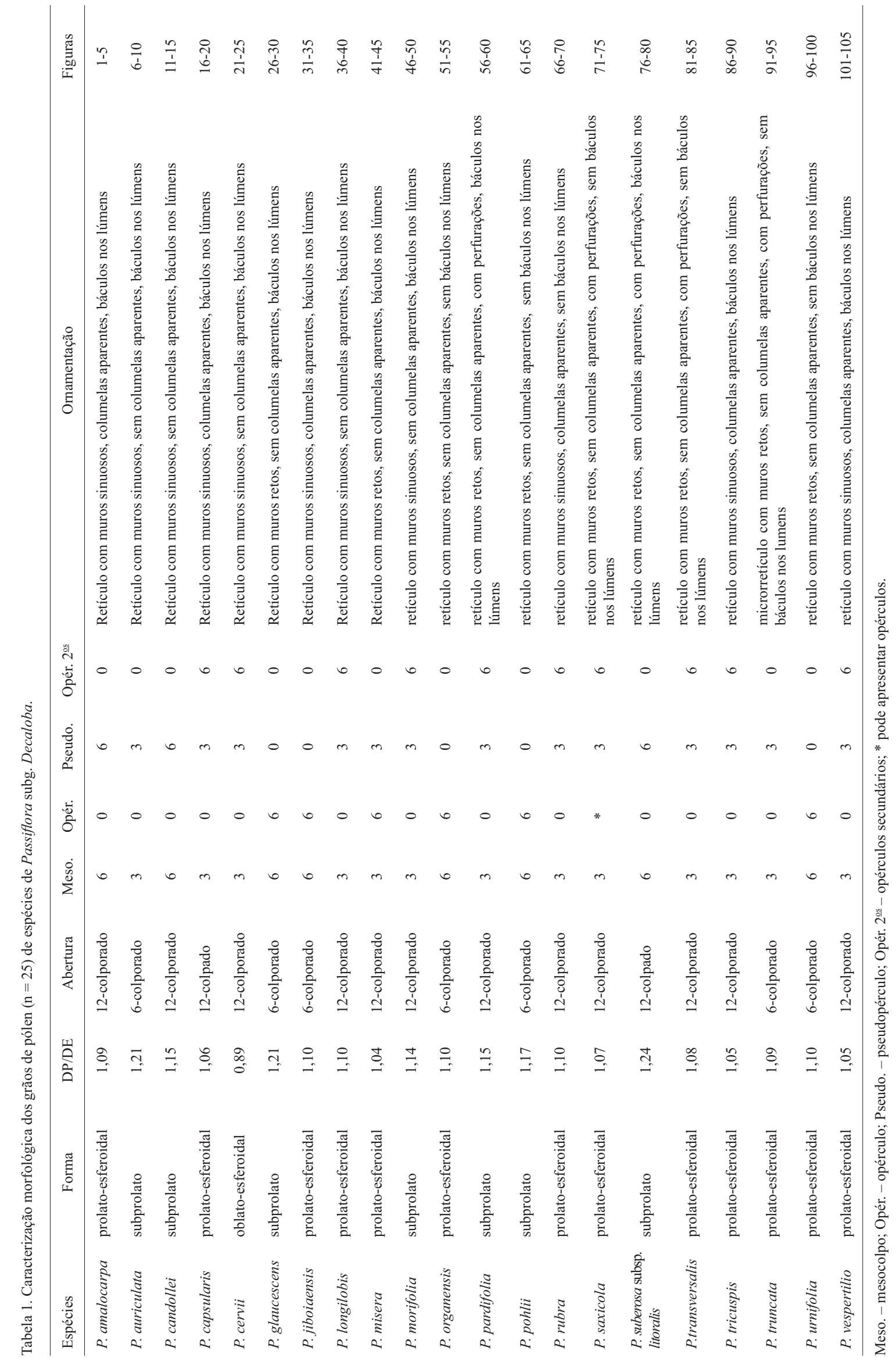


Tabela 2. Mediadas $(\mathrm{em} \mu \mathrm{m})$ dos grãos de pólen em vista equatorial $(\mathrm{n}=25)$ de espécies de Passiflora subg. Decaloba $. \overline{\mathrm{x}}=$ média aritimética; $\mathrm{s} \overline{\mathrm{x}}=$ desvio padrão da média; I.C. = intervalo de confiança.

\begin{tabular}{|c|c|c|c|c|c|c|}
\hline & \multicolumn{3}{|c|}{ Diâmetro polar } & \multicolumn{3}{|c|}{ Diâmetro equatorial } \\
\hline & Faixa de variação & $\overline{\mathrm{X}} \pm \mathrm{S}_{\overline{\mathrm{x}}}$ & I.C. $95 \%$ & Faixa de variação & $\overline{\mathrm{X}} \pm \mathrm{S}_{\overline{\mathrm{x}}}$ & I.C. $95 \%$ \\
\hline P. amalocarpa & $56,0-59,5$ & $57,3 \pm 0,2$ & $56,9-57,7$ & $49,0-55,0$ & $52,4 \pm 0,3$ & $51,9-53,1$ \\
\hline P. auriculata & $57,5-77,5$ & $66,4 \pm 0,2$ & $63,8-68,6$ & $47,5-60,0$ & $54,8 \pm 0,8$ & $53,2-56,4$ \\
\hline P. candollei & $55,0-57,5$ & $56,7 \pm 0,2$ & $56,8-57,1$ & $47,5-50,0$ & $49,1 \pm 0,2$ & $48,7-49,5$ \\
\hline P. capsularis & $47,5-57,5$ & $53,7 \pm 0,5$ & $52,7-54,7$ & $47,5-55,0$ & $50,4 \pm 0,5$ & $49,4-51,4$ \\
\hline P. cervii & $47,5-55,0$ & $50,7 \pm 0,5$ & $49,7-51,7$ & $52,5-60,0$ & $56,7 \pm 0,4$ & $55,9-57,5$ \\
\hline P. glaucescens & $55,0-66,0$ & $57,4 \pm 0,4$ & $56,7-58,1$ & $45,0-50,0$ & $47,4 \pm 0,4$ & $46,6-48,2$ \\
\hline P. jiboiaensis & $52,5-55,0$ & $53,9 \pm 0,2$ & $53,5-54,3$ & $47,5-52,5$ & $48,7 \pm 0,3$ & $48,1-49,3$ \\
\hline P. longilobis & $52,5-60,0$ & $57,3 \pm 0,4$ & $56,5-58,1$ & $47,5-55,0$ & $51,9 \pm 0,4$ & $51,1-52,7$ \\
\hline P. misera & $47,5-57,5$ & $53,0 \pm 0,6$ & $51,8-54,2$ & $47,5-55,0$ & $51,0 \pm 0,5$ & $50,0-52,0$ \\
\hline P. morifolia & $57,5-67,5$ & $62,0 \pm 0,7$ & $60,6-63,4$ & $50,0-65,0$ & $54,5 \pm 0,9$ & $52,7-56,3$ \\
\hline P. organensis & $50,0-62,5$ & $58,5 \pm 0,7$ & $57,0-59,9$ & $50,0-57,5$ & $53,3 \pm 0,4$ & $52,5-54,1$ \\
\hline$P$. pardifolia & $50,0-57,5$ & $54,5 \pm 0,5$ & $53,5-55,5$ & $45,0-50,0$ & $47,0 \pm 0,4$ & $46,2-47,8$ \\
\hline P. pohlii & $47,5-57,5$ & $52,9 \pm 0,5$ & $51,9-53,9$ & $42,5-47,5$ & $45,0 \pm 0,3$ & $44,4-45,6$ \\
\hline P. rubra & $47,5-57,5$ & $52,7 \pm 0,5$ & $51,7-53,7$ & $42,5-52,5$ & $48,0 \pm 0,6$ & $46,8-49,2$ \\
\hline P. saxicola & $50,0-57,5$ & $54,4 \pm 0,4$ & $53,6-55,2$ & $45,0-57,5$ & $50,9 \pm 1,0$ & $48,8-53,0$ \\
\hline P. suberosa subsp. litoralis & $65,0-70,0$ & $66,6 \pm 0,3$ & $65,9-67,3$ & $50,0-57,5$ & $53,7 \pm 0,5$ & $52,6-54,8$ \\
\hline P. transversalis & $45,0-57,5$ & $52,3 \pm 0,6$ & $51,1-53,5$ & $42,5-52,5$ & $48,5 \pm 0,6$ & $47,3-49,7$ \\
\hline P. tricuspis & $52,5-57,5$ & $54,9 \pm 0,4$ & $52,9-56,3$ & $45,0-55,0$ & $51,9 \pm 0,6$ & $46,0-52,5$ \\
\hline P. truncata & $47,5-52,5$ & $50,6 \pm 0,5$ & $49,6-51,6$ & $45,0-50,0$ & $46,3 \pm 0,3$ & $45,7-47,0$ \\
\hline P. urnifolia & $57,5-62,5$ & $60,9 \pm 0,3$ & $60,3-61,5$ & $52,5-57,5$ & $55,4 \pm 0,4$ & $54,6-56,2$ \\
\hline P. vespertilio & $50,0-57,5$ & $55,2 \pm 0,5$ & $54,2-56,2$ & $50,0-57,5$ & $52,5 \pm 0,5$ & $51,5-53,5$ \\
\hline
\end{tabular}

Tabela 3. Médias (em $\mu \mathrm{m}$ ) do diâmetro equatorial (DEVP), lado do apocolpo (LA) e índice de área polar (IAP), em vista polar $(\mathrm{n}=10)$ de espécies de Passiflora subg. Decaloba.

\begin{tabular}{lccc}
\hline Espécies & DEVP & LA & IAP \\
\hline P. amalocarpa & 60,2 & 12,5 & 0,20 \\
P. auriculata & 75,1 & 20,9 & 0,27 \\
P. candollei & 44,2 & 8,7 & 0,20 \\
P. capsularis & 57,0 & 12,3 & 0,22 \\
P. cervii & 57,3 & 13,3 & 0,23 \\
P. glaucescens & 66,5 & 11,1 & 0,17 \\
P. jiboiaensis & 56,6 & 10,5 & 0,18 \\
P. longilobis & 55,5 & 11,0 & 0,20 \\
P. misera & 52,2 & 11,7 & 0.22 \\
P. morifolia & 66,7 & 18,0 & 0,27 \\
P. organensis & 56,5 & 15,0 & 0,26 \\
P. pardifolia & 51,0 & 10,5 & 0,21 \\
P. pohlii & 44,0 & 13,5 & 0,31 \\
P. rubra & 59,5 & 10,5 & 0,18 \\
P. saxicola & 58,0 & 12,0 & 0,21 \\
P. suberosa subsp. litoralis & 75,0 & 19,5 & 0,26 \\
P. transversalis & 54,0 & 12,3 & 0,23 \\
P. tricuspis & 54,1 & 8,8 & 0,16 \\
P. truncata & 51,2 & 9,4 & 0,18 \\
P. urnifolia & 67,0 & 16,0 & 0,24 \\
P. vespertilio & 57,0 & 12,8 & 0,22 \\
\hline & & & \\
\hline
\end{tabular}

Os grãos de pólen podem apresentar três mesocolpos $[P$. auriculata (Fig. 6), P. capsularis (Fig. 16), P. cervii (Fig. 22), $P$. longilobis (Fig. 37), P. misera (Fig. 42), P. morifolia (Fig. 47), P. pardifolia (Fig. 56), P. rubra (Fig. 66), P. saxicola (Fig. 72), P. transversalis (Fig. 81), P. tricuspis (Fig. 86), P. truncata (Fig. 91)e P. vespertilio (Fig. 102)] ou seis mesocolpos [P. amalocarpa (Fig. 1), P. candollei (Fig. 12), P. glaucescens (Fig. 26), P. jiboiaensis (Fig. 31), P. organensis (Fig. 52), P. pohlii (Fig. 64), P. suberosa subsp. litoralis (Fig. 77) e P. urnifolia (Fig. 97)] (Tab. 1).

Os colpos são longos, com comprimento variando de $28,0 \mu \mathrm{m}$ (em P. rubra) a $62,8 \mu \mathrm{m}$ (em P. capsularis); quanto à largura, os colpos são estreitos na maioria dos táxons, sendo mais largos os de $P$. transversalis $(10,8 \mu \mathrm{m})$. Nos grãos de pólen colporados, as endoaberturas são lolongadas e o comprimento da endoabertura, na maioria das espécies, varia entre $9,9 \mu \mathrm{m}$ (P. morifolia) a 19,3 $\mu \mathrm{m}(P$. saxicola). Quanto à largura, o menor valor $(1,5 \mu \mathrm{m})$ é apresentado por P. glaucescens e o maior valor (10,0 $\mu \mathrm{m})$, em P. pohlii (Tab. 4).

Podem ser encontrados opérculos, pseudopérculos e/ou opérculos secundários nas seguintes espécies: a) opérculos em P. glaucescens (Fig. 27), P. jiboiaensis (Fig. 31), P. misera (Fig. 42), P. organensis (Fig. 54), P. pohlii (Fig. 64) e P. urnifolia (Fig. 97, 99);

b) pseudopérculos em P. amalocarpa (Fig. 2), P. auriculata (Fig. 9), P. candollei (Fig. 12, 14), P. capsularis (Fig. 16), P. cervii (Fig. 22, 24), P. longilobilis (Fig. 37), P. misera (Fig. 42, 44), P. morifolia (Fig. 47), P. pardifolia (Fig. 57, 59), P. 
rubra (Fig. 66, 67), P. saxicola (Fig. 72, 74), P. suberosa subsp. litoralis (Fig. 77, 79), P. transversalis (Fig. 82), P. tricuspis (Fig. 87), P. truncata (Fig. 92) e P. vespertilio (Fig. 102, 104);

c) e/ou opérculos secundários em $P$. capsularis (Fig. 19), P. cervii (Fig. 22, 24), P. longilobilis (Fig. 37, 39), P. morifolia (Fig. 47), P. pardifolia (Fig. 57, 59), P. rubra (Fig. 67, 69), P. saxicola (Fig. 72, 74), P. transversalis (Fig. 82), P. tricuspis (Fig. 87) e P. vespertilio (Fig. 102, 104).

A exina é heterorreticulada ou microrreticulada (P. truncata, Fig. 95), com muros simples sinuosos (Fig. 5, 10, 15, 20, 50, 70) ou retos (Fig. 55, 60, 65, 80, 95), sempre estreitos, columelados, columelas visíveis quando o muro é alto (Fig. $35,70,90,105$ ) ou não visíveis (Fig. 40, 55, 75, 85, 95, 100), com ou sem perfurações. A sexina microrreticulada, retículos com lumens pequenos $(\leq 4,2 \mu \mathrm{m})$ ou grandes $(\geq 5,5 \mu \mathrm{m})$ (Tab. 1, 5), possuindo ou não báculos (Fig. 55, 65, 70, 75, $85,95,100)$ no interior dos lumens. Em todos os táxons, a sexina é simplescolumelada e mais espessa do que a nexina.

O material usado como comparação dos resultados (Tab. 6) se manteve, em sua maioria, fora dos limites do intervalo de confiança e/ou da faixa de variação quando comparado com o respectivo material padrão, demonstrando a grande variabilidade existente na forma dos grãos de pólen.

Diferentes características palinológicas encontradas nesse estudo têm se mostrado de valor diagnóstico para distinguir táxons ou, às vezes, grupos de táxons e que possibilitam o uso desses atributos na elaboração de uma chave analítica auxiliar à taxonomia do grupo.

Chave polínica para identificação das espécies de Passiflora subg. Decaloba ocorrentes no Brasil

1. Grãos de pólen colpados

2. Grãos de pólen com 3 mesocolpos, presença de opérculos secundários, retículos com muros sinuosos .....P. capsularis

2'. Grãos de pólen com 6 mesocolpos, ausência de opérculos secundários, retículos com muros retos

P. suberosa subsp. litoralis

1'. Grãos de pólen colporados

3. Grãos de pólen 6-colporados

4. Grãos de pólen com 3 mesocolpos, ausência de opérculos, 3 pseudopérculos

5. Sexina reticulada, muros sinuosos. P. auriculata

5'. Sexina microreticulada, muros retos

P. truncata

4'. Grãos de pólen com 6 mesocolpos, 6 opérculos, ausência de pseudopérculos

6. Retículos com muros sinuosos.

P. jiboiaensis

6'. Retículos com muros retos

7. Lumens do retículo com báculos no interior.

P. glaucescens

7'. Lumens do retículo sem báculos no interior

8. Média do diâmetro dos lumens do retículo $>2,0 \mu \mathrm{m}$

P. organensis

8'. Média do diâmetro dos lumens do retículo $<2,0 \mu \mathrm{m}$

9. Grãos de pólen subprolatos, I.C. 95\% do diâmetro polar 51,9-53,9

9'. Grãos de pólen prolato-esferoidais, I.C. $95 \%$ do diâmetro polar $60,3-61,5 \mu \mathrm{m}$.........P. urnifolia

3'. Grãos de pólen 12-colporados

10. Grãos de pólen com 6 mesocolpos

11. Grãos de pólen prolato-esferoidais .................................................... amalocarpa

11'.Grãos de pólen subprolatos................................................................. candollei

10'. Grãos de pólen com 3 mesocolpos

$12^{\prime}$.Retículos com muros retos

13. Lumens do retículo com báculos no interior

P. misera

13'.Lumens do retículo sem báculos no interior

14. Grãos de pólen subprolatos.

P. pardifolia

14'.Grãos de pólen prolato-esferoidais ...............P. saxicola e $P$. transversalis

12. Retículos com muros sinuosos

15. Média do diâmetro dos lumens do retículo $<3,5 \mu \mathrm{m}$

P. longilobis

15'. Média do diâmetro dos lumens do retículo $\geq 3,5 \mu \mathrm{m}$

16. Média do comprimento do colpo $\leq 30 \mu \mathrm{m}$ P. rubra

16'. Média do comprimento do colpo $>30 \mu \mathrm{m}$

17. Média do diâmetro dos lumens do retículo $\geq 8,0 \mu \mathrm{m}$

P. morifolia

17'.Média do diâmetro dos lumens do retículo $<8,0 \mu \mathrm{m}$

18. Grãos de pólen oblato-esferoidais........................... cervii

18'. Grãos de pólen prolato-esferoidais 
Acta bot. bras. 24(1): 133-145. 2010.

Tabela 4. Médias $(\mathrm{em} \mu \mathrm{m})$ das medidas das aberturas do pólen $(\mathrm{n}=10)$ de espécies de Passiflora subg. Decaloba.

\begin{tabular}{|c|c|c|c|c|}
\hline \multirow{2}{*}{ Espécies } & \multicolumn{2}{|c|}{ Colpo } & \multicolumn{2}{|c|}{ Endoabertura } \\
\hline & compr. & larg. & compr. & larg. \\
\hline P. amalocarpa & 52,7 & 1,1 & 12,4 & 6,8 \\
\hline P. auriculata & 50,0 & 3,7 & 12,3 & 7,7 \\
\hline P. candollei & 29,5 & 2,7 & 10,0 & 7,5 \\
\hline P. capsularis & 62,8 & 5,5 & - & - \\
\hline P. cervii & 59,0 & 5,5 & 12,5 & 7,8 \\
\hline P. glaucescens & 46,2 & 1,3 & 14,0 & 1,5 \\
\hline P. jiboiaensis & 42,5 & 3,7 & 11,2 & 7,5 \\
\hline P. longilobis & 41,7 & 3,4 & 11,3 & 7,5 \\
\hline P. misera & 40,5 & 2,5 & 11,7 & 7,7 \\
\hline P. morifolia & 44,0 & 2,9 & 9,9 & 7,9 \\
\hline P. organensis & 38,5 & 3,3 & 12,5 & 9,3 \\
\hline P. pardifolia & 30,0 & 2,5 & 10,3 & 7,5 \\
\hline P. pohlii & 41,5 & 6,2 & 12,5 & 10,0 \\
\hline P. rubra & 28,0 & 6,3 & 10,3 & 7,8 \\
\hline P. saxicola & 55,8 & 4,3 & 19,3 & 5,5 \\
\hline P. suberosa subsp. litoralis & 38,1 & 3,6 & - & - \\
\hline P. transversalis & 40,5 & 10,8 & 11,5 & 6,5 \\
\hline P. tricuspis & 39,2 & 2,7 & 10,7 & 7,7 \\
\hline P. truncata & 36,5 & 2,7 & 12,0 & 7,5 \\
\hline P. urnifolia & 38,3 & 3,3 & 10,5 & 5,0 \\
\hline P. vespertilio & 43,7 & 1,3 & 10,8 & 6,2 \\
\hline
\end{tabular}

Tabela 5. Médias (em $\mu \mathrm{m})$ da medida das camadas de exina e diâmetro do lúmen dos grãos de pólen (n =10) de espécies de Passiflora subg. Decaloba.

\begin{tabular}{|c|c|c|c|c|}
\hline Espécies & exina & sexina & nexina & lúmen \\
\hline P. amalocarpa & 2,0 & 1,8 & 0,2 & 5,6 \\
\hline P. auriculata & 1,8 & 1,6 & 0,1 & 1,5 \\
\hline P. candollei & 1,9 & 1,0 & 0,9 & 4,0 \\
\hline P. capsularis & 2,4 & 2,1 & 0,3 & 4,0 \\
\hline P. cervii & 2,0 & 1,8 & 0,2 & 4,1 \\
\hline P. glaucescens & 1,8 & 1,6 & 0,1 & 2,3 \\
\hline P. jiboiaensis & 2,0 & 1,0 & 0,9 & 4,0 \\
\hline P. longilobis & 2,0 & 1,0 & 1,0 & 2,5 \\
\hline P. misera & 2,6 & 1,8 & 1,0 & 2,5 \\
\hline P. morifolia & 2,0 & 1,9 & 0,1 & 8,7 \\
\hline P. organensis & 2,9 & 1,9 & 1,0 & 3,0 \\
\hline P. pardifolia & 1,9 & 1,0 & 0,9 & 1,2 \\
\hline P. pohlii & 1,9 & 1,0 & 0,9 & 1,8 \\
\hline P. rubra & 2,0 & 1,1 & 0,9 & 4,1 \\
\hline P.saxicola & 1,9 & 1,8 & 0,1 & 3,7 \\
\hline P. suberosa subsp. litoralis & 1,8 & 1,7 & 0,1 & 2,7 \\
\hline P. transversalis & 2,0 & 1,1 & 0,9 & 1,6 \\
\hline P. tricuspis & 1,7 & 1,3 & 0,1 & 3,8 \\
\hline P. truncata & 1,0 & 0,9 & 0,1 & 0,7 \\
\hline P. urnifolia & 1,5 & 1,4 & 0,1 & 1,8 \\
\hline P. vespertilio & 1,9 & 1,7 & 0,2 & 4,2 \\
\hline
\end{tabular}


Tabela 6. Medidas (em $\mu \mathrm{m})$ dos grãos de pólen, em vista equatorial, dos materiais de comparação (n=10) de espécies de Passiflora subg. Decaloba.

\begin{tabular}{|c|c|c|c|c|c|c|}
\hline \multirow{2}{*}{ Espécies } & \multicolumn{2}{|c|}{ Diâmetro polar } & \multicolumn{2}{|c|}{ Diâmetro equatorial } & \multirow{2}{*}{$\mathrm{DP} / \mathrm{DE}$} & \multirow{2}{*}{ Forma } \\
\hline & Faixa de variação & $\overline{\mathrm{x}}$ & Faixa de variação & $\overline{\mathrm{x}}$ & & \\
\hline \multicolumn{7}{|l|}{ P. amalocarpa } \\
\hline R.L. Fróes 29041 & $56,0-59,5$ & 57,4 & $49,5-55,0$ & 52,3 & 1,09 & Prolato-esferoidal \\
\hline J.G. Kuhlmann $s / n$ & $55,5-59,0$ & 57,3 & $49,5-55,5$ & 51,9 & 1,10 & Prolato-esferoidal \\
\hline \multicolumn{7}{|l|}{ P. auriculata } \\
\hline E.A. Anunciação et al. 853 & $57,5-77,5$ & 66,3 & $47,5-60,0$ & 54,8 & 1,20 & Subprolata \\
\hline A.P. Duarte 1213 & $57,0-77,0$ & 66,1 & $47,0-55,5$ & 54,6 & 1,21 & Subprolata \\
\hline J.M. Íris 395 & $57,5-77,0$ & 62,9 & $47,5-60,0$ & 54,1 & 1,16 & Subprolata \\
\hline \multicolumn{7}{|l|}{ P. candollei } \\
\hline A.Ducke s/n & $50,0-57,5$ & 55,3 & $50,0-55,0$ & 52,0 & 1,06 & Prolato-esferoidal \\
\hline A.P. Duarte 7289 & $52,5-57,5$ & 55,2 & $47,5-52,5$ & 50,5 & 1,09 & Prolato-esferoidal \\
\hline J. G. Kuhlmann 922 & $50,0-57,5$ & 55,8 & $50,0-55,0$ & 51,9 & 1,07 & Prolato-esforoidal \\
\hline \multicolumn{7}{|l|}{ P. capsularis } \\
\hline Reitz et Klein 16649 & $50,0-57,5$ & 53,8 & $47,5-52,5$ & 49,8 & 1,08 & Prolato-esferoidal \\
\hline G.Hatschbach 47634 & $47,5-60,0$ & 56,1 & $50,0-57,5$ & 54,0 & 1,04 & Prolato-esferoidal \\
\hline O. Bueno 4963 & $50,0-60,0$ & 56,8 & $47,5-57,5$ & 52,8 & 1,07 & Prolato-esferoidal \\
\hline \multicolumn{7}{|l|}{ P. cervii } \\
\hline P.I. Oliveira 691 & $55,0-65,0$ & 56,0 & $55,0-62,5$ & 60,5 & 0,92 & Oblato-esferoidal \\
\hline A. Sehnen 2430 & $47,5-55,0$ & 52,5 & $52,5-62,5$ & 58,0 & 0,90 & Oblato-esferoidal \\
\hline E.P. Heringer 6578 & $47,5-55,0$ & 50,8 & $52,5-62,5$ & 58,3 & 0,87 & Suboblata \\
\hline \multicolumn{7}{|l|}{ P. glaucescens } \\
\hline Kraenzlin et Schlechter $s / n$ & $55,0-66,0$ & 57,3 & $45,5-50,5$ & 47,5 & 1,20 & Subprolata \\
\hline \multicolumn{7}{|l|}{ P. longilobis } \\
\hline \multicolumn{7}{|l|}{ I. Cordeiro et al. 976} \\
\hline P. misera & $52,5-60,0$ & 57,3 & $47,5-55,0$ & 51,9 & 1,10 & Prolato-esferoidal \\
\hline C. Franco et $P$. Mendes $s / n$ & $47,5-60,0$ & 53,0 & $47,5-57,5$ & 50,3 & 1,05 & Prolato-esferoidal \\
\hline \multicolumn{7}{|l|}{ P. morifolia } \\
\hline F. Chagas e Silva 1271 & $57,5-72,5$ & 63,2 & $50,0-65,0$ & 55,3 & 1,14 & Subprolata \\
\hline W. Heohne $s / n$ & $66,1-66,3$ & 66,2 & $50,0-57,5$ & 53,8 & 1,23 & Subprolata \\
\hline \multicolumn{7}{|l|}{ P. organensis } \\
\hline A.L. Peixoto et al. 480 & $52,5-62,5$ & 58,5 & $50,0-57,5$ & 54,0 & 1,08 & Prolato-eferoidal \\
\hline A. Gentry et al. 49692 & $52,5-65,0$ & 59,3 & $52,5-57,5$ & 55,3 & 1,07 & Prolato-esferoidal \\
\hline M.L. Gavillanis et F. Frieiro 4850 & $47,5-52,5$ & 50,0 & $37,5-42,5$ & 40,5 & 1,23 & Subprolata \\
\hline E. Pereira et al. 4056 & $57,5-65,0$ & 61,5 & $52,5-60,0$ & 56,5 & 1,09 & Prolato-esferoidal \\
\hline R. Marquete et al. 211 & $47,5-52,5$ & 49,7 & $37,5-42,5$ & 39,7 & 1,25 & Subprolata \\
\hline s/ col & $55,0-65,0$ & 59,8 & $52,5-60,0$ & 56,0 & 1,07 & Prolato-esferoidal \\
\hline D.B. Falkemberg et al. 4143 & $52,5-62,5$ & 54,3 & $50,0-60,0$ & 54,0 & 1,00 & Esferoidal \\
\hline J.A. Jarenkow et D.B. Falkemberg 2298 & $52,5-62,5$ & 58,0 & $50,0-57,5$ & 54,8 & 1,06 & Prolato-esferoidal \\
\hline \multicolumn{7}{|l|}{ P.pohlii } \\
\hline E.P. Heringer 18528 & $42,5-47,5$ & 44,5 & $35,0-40,0$ & 37,5 & 1,19 & Subprolata \\
\hline M.L. Fonseca et al. 1567 & $55,0-62,5$ & 58,6 & $47,5-50,0$ & 49,0 & 1,19 & Subprolata \\
\hline H.S. Irwin et T.R. Soderstrom 5559 & $52,5-57,5$ & 54,7 & $45,0-50,0$ & 47,0 & 1,16 & Subprolata \\
\hline F. Frieiro-Costa $s / n$ & $40,0-45,0$ & 43,0 & $35,0-40,0$ & 38,2 & 1,12 & Prolato-esferoidal \\
\hline M.P. Coons 78-1131 & $52,5-57,5$ & 56,0 & $50,0-52,5$ & 51,5 & 1,08 & Ptolato-esferoidal \\
\hline E.P. Heringer 3589 & $50,0-57,5$ & 54,7 & $42,5-52,5$ & 46,7 & 1,17 & Subprolata \\
\hline
\end{tabular}


Tabela 6. Continuação

\begin{tabular}{|c|c|c|c|c|c|c|}
\hline \multirow{2}{*}{ Espécies } & \multicolumn{2}{|c|}{ Diâmetro polar } & \multicolumn{2}{|c|}{ Diâmetro equatorial } & \multirow{2}{*}{$\mathrm{DP} / \mathrm{DE}$} & \multirow{2}{*}{ Forma } \\
\hline & Faixa de variação & $\overline{\mathrm{x}}$ & Faixa de variação & $\overline{\mathrm{x}}$ & & \\
\hline E.P. heringer 6579 & $50,0-57,5$ & 54,2 & $45,0-55,0$ & 49,2 & 1,10 & Prolato-esferoidal \\
\hline \multicolumn{7}{|l|}{ P. rubra } \\
\hline Z. Trinta et al. 1270 & $47,5-55,0$ & 53,0 & $45,0-52,5$ & 47,8 & 1,11 & Prolato-esferoidal \\
\hline A. Fernandes $s / n$ & $47,5-55,0$ & 51,3 & $45,0-52,5$ & 48,0 & 1,07 & Prolato-esferoidal \\
\hline L.P. Félix 1527 & $47,5-55,0$ & 51,5 & $45,0-52,5$ & 47,8 & 1,08 & Prolato-esferoidal \\
\hline \multicolumn{7}{|l|}{ P.saxicola } \\
\hline F. Chagas e Silva et R.C. Mendonça 151 & $47,5-57,5$ & 53,0 & $47,5-52,5$ & 50,8 & 1,04 & Prolato-esferoidal \\
\hline \multicolumn{7}{|l|}{ P. suberosa subsp. litoralis } \\
\hline J. Larocca $s / n$ & $65,5-70,0$ & 66,4 & $50,5-57,5$ & 53,1 & 1,25 & Subprolata \\
\hline \multicolumn{7}{|l|}{ P. transversalis } \\
\hline P. Dúsen 3085 & $50,0-57,5$ & 53,2 & $45,0-57,5$ & 51,6 & 1,03 & Prolato-esferoidal \\
\hline L.B. Smith et R. Reitz $s / n$ & $47,5-57,5$ & 53,0 & $47,5-52,5$ & 50,0 & 1,06 & Prolato-esferoidal \\
\hline M.L. Abruzzi 877 & $50,0-57,5$ & 53,3 & $47,5-52,5$ & 49,8 & 1,07 & Prolato-esferoidal \\
\hline O. Bueno 3788 & $50,0-60,0$ & 55,0 & $50,0-57,5$ & 54,5 & 1,01 & Prolato-esferoidal \\
\hline \multicolumn{7}{|l|}{ P. tricuspis } \\
\hline F.C. Campos Neto $s / n$ & $60,0-67,5$ & 63,4 & $57-5-62,5$ & 60,2 & 1,05 & Prolato-esferoidal \\
\hline \multicolumn{7}{|l|}{ P. truncata } \\
\hline M.B. Cosori et al. 166 & $47,5-55,0$ & 51,0 & $45,0-55,0$ & 48,7 & 1,05 & prolato-esferoidal \\
\hline Brade $s / n$ & $45,0-57,5$ & 52,0 & $40,0-52,5$ & 45,9 & 1,13 & prolato-esferoidal \\
\hline \multicolumn{7}{|l|}{ P. vespertilio } \\
\hline G. Martinelli et al. 7000 & $50,0-57,5$ & 54,8 & $50,0-57,5$ & 51,8 & 1,06 & Prolato-esferoidal \\
\hline R.L. Fróes 25791 & $45,0-57,5$ & 53,0 & $50,0-57,5$ & 52,8 & 1,00 & Esferoidal \\
\hline
\end{tabular}

\section{Discussão e conclusão}

Em seu trabalho, Presting (1965) descreveu, dentre outros, os grãos de pólen das espécies $P$. auriculata, $P$. capsularis, P. misera, P. morifolia, P. organensis, P. pohlii e P. suberosa utilizando, basicamente, o número e tipo de abertura, estrutura da sexina e a presença ou não de opérculo secundário. Presting (1965) considerou, assim, que grãos de pólen: 6-colporados com 3 mesocolpos, 3 pseudopérculos e 6 opérculos secundários eram encontrados em $P$. auriculata, P. misera, P. morifolia e $P$. suberosa; 6-colporados com 6 mesocolpos e 6 opérculos secundários eram encontrados em $P$. organensis e grãos de pólen 12-colporados com 3 mesocolpos, 3 pesudopérculos e 6 opérculos secundários em $P$. capsularis e P. pohlii, além de colpos livres, tendendo ao concrescimento aos pares ou de quatro em quatro, em $P$. capsularis. Estes resultados assemelham-se aos encontrados no presente estudo, no que se refere à forma e ornamentação da sexina diferindo, porém nas características de $P$. misera e $P$. morifolia por possuírem grãos de pólen 12-colporados, de P. suberosa (12-colpados) e de $P$. organensis que, aqui foi considerado como tendo grãos de pólen apenas com opérculos.

Huynh (1972) estudou o arranjo dos grãos de pólen de Passiflora ainda na fase de tétrade, procurando relacionar a organização dos colpos e mesocolpos em grãos de pólen livres com aqueles da tétrade pós-meiótica. $\mathrm{O}$ autor analisou cinco espécies, das quais duas (P. capsularis e P. suberosa) também foram aqui estudadas. Considerou que $P$. capsularis possui 12 cólporos estreitos, com endoaberturas muito estreitas, enquanto $P$. suberosa tem grãos de pólen com seis cólporos. Segundo o autor, o mesmo grão de pólen pode apresentar diferentes tamanhos de mesocolpo e este fato está relacionado com a fase de tétrade, onde os micrósporos de cada par de micrósporosirmãos estarão diametralmente opostos a um mesocolpo mais largo. Os resultados encontrados no presente estudo para $P$. capsularis foram semelhantes no que se refere ao número de colpos. No entanto, em $P$. suberosa os grãos de pólen foram identificados, aqui, como 12-colpados. A correlação com a fase de tétrade não pode ser realizada no presente estudo.

Roubik \& Moreno (1991) realizaram um estudo polínico de espécies de várias famílias ocorrentes na Ilha de Barro Colorado, Panamá. Dentre as famílias estudadas, Passifloraceae foi objeto de interesse, com 11 espécies de Passiflora. Para estes autores, o grão de pólen típico da família apresenta vista polar trirradial, com 3-9 pré-opérculos, correspondendo às áreas livres nos intercolpos. Estes pré-opérculos são formados pela união de pares de colpos adjacentes, parecendo um anel longitudinal contínuo. No presente estudo, o termo 
pré-opérculo senso Roubik \& Moreno (1991) foi considerado como pseudopérculo. Quanto às demais características descritas por estes autores para as espécies de Passiflora, na sua maioria, também foram aqui observadas, apesar de se tratarem de outras espécies.

MacDougal (1994) fez a revisão do subgênero Decaloba seção Pseudodysosmia, estudando 18 espécies, entre elas $P$. morifolia. Os grãos de pólen foram considerados de oblatos a esferoidais, 6-colporados a 6-sincolporados, grosseiramente reticulados e com columelas comuns expostas, com aproximadamente entre $40-65 \mu \mathrm{m}$ de diâmetro. Os resultados obtidos no presente estudo foram semelhantes aos encontrados por este autor no que se refere ao tamanho e à ornamentação da sexina, porém a forma encontrada para os pólens de $P$. morifolia foi subprolata, além de serem 12-colporados.

Garcia et al. (2002), analisando a ontogenia e a palinologia de seis espécies de Passiflora pertencentes a três subgêneros - Passiflora, Dysosmia e Decaloba -, estudaram os grãos de pólen de $P$. misera e P. suberosa. Segundo os autores, as medidas polínicas $(\mathrm{n}=10)$ foram realizadas em microscópio de luz, com grãos de pólen não acetolisados, montados apenas em água glicerinada, pois o material submetido à acetólise variou consideravelmente na forma. Os resultados encontrados por estes autores diferem dos observados no presente estudo, uma vez que os grãos de pólen das espécies acima citadas são descritos como sendo geminicolpados, com seis pares de colpos que estão anastomosados nos polos. No presente estudo, os grãos de pólen foram definidos como possuindo pseudopérculos e os colpos não são geminicolpados nem sincolpados.

Milward-de-Azevedo et al. (2004) analisaram oito espécies de Passiflora subg. Decaloba ocorrentes no Sudeste do Brasil, mostrando que os pólens desse grupo possuem grande importância para distinguir espécies, pois apresentam características diagnósticas em nível específico, principalmente em relação aos táxons afins. Neste trabalho, as espécies foram distinguidas pelo número de colpos, presença ou ausência de cólporos, muros retos ou sinuosos e dimensões dos diâmetros do lúmen. Os resultados obtidos no presente trabalho foram semelhantes aos encontrados por estes autores no que se refere ao tamanho, retículo, diâmetro dos lumens e à espessura da exina, porém $P$. capsularis e $P$. organensis foram descritas equivocadamente como 12-colporadas.

Araújo \& Santos (2004) realizaram um estudo polínico em doze espécies de Passiflora ocorrentes na Chapada Diamantina, Bahia. Estabeleceram três tipos polínicos, considerando-se os tipos operculares, as aberturas e a escultura da exina. As espécies do subgênero Decaloba (P. misera e $P$. suberosa) foram incluídas no tipo 3, por apresentarem grãos de pólen com opérculos elípticos, exina reticulada e monomórficos (6-colpados), além do uso do termo pontopérculo, ao invés de pseudopérculo. No presente estudo, os grãos de pólen de P. suberosa são caracterizados como 12-colpados.

Barrios et al. (2005) apresentam a caracterização polínica dos gêneros Dilkea e Passiflora e seus subgêneros. É descrito para o subgênero Decaloba, grãos de pólen médios a grandes, suboblatos a prolatos, exceto esferoidais, 6-colporados a 12-colporados, colpos livres, com tendência a fusão ou fusionados aos pares. Foi constatado, no atual estudo, a presença de grãos de pólen subprolatos a prolatos, além de grãos de pólen colpados.

Milward-de-Azevedo (dados não publicados) realizou a primeira análise filogenética morfológica para as espécies de Passiflora subg. Decaloba ocorrentes no Brasil utilizando entre outros, dez caracteres morfológicos baseados em dados polínicos. A inclusão destes caracteres na análise cladística gerou conflitos com a recente classificação desse grupo em superseções e seções proposta por Feuillet \& MacDougal (2003).

Assim, diversas características polínicas têm se mostrado de valor diagnóstico específico para a taxonomia do subgênero Decaloba, como número de colpos, mesocolpos, pseudopérculos e opérculos secundários, presença ou ausência de endoabertura, retículos com muros sinuosos ou retos, diâmetros dos lumens dos retículos, presença ou ausência de báculos e comprimento dos colpos. Esses caracteres podem diferenciar os táxons entre si, além de circunscrever o subgênero Decaloba como uma categoria taxonômica autônoma no sistema de classificação de Feuillet \& MacDougal (2003).

Entretanto, como pode ser observado na chave polínica apresentada, Passiflora tricuspis e P. vespertilio, P. saxicola e $P$. transversalis possuem grãos de pólen morfologicamente muito semelhantes, não apresentando características polínicas diagnósticas para separá-las entre si. Passiflora pohlii e P. urnifolia ficaram separadas na chave, apenas pelos valores do intervalo de confiança, essa separação é confirmada pelos estudos de Milward-de-Azevedo (2008), onde essas espécies constituem táxons autônomos, sendo distintos por características morfológicas vegetativas e florais. Passiflora pohlii possui folhas cuneiformes, flores com filamentos externos da corona liguliformes, livres e filamentos internos liguliformes, com ápice capitado e límen lobulado, enquanto $P$. urnifolia distingue-se pelas folhas papilioniformes, flores com filamentos externos da corona filiformes, unidos por membrana e filamentos internos filiformes, com ápice 3-lobado, e lumen anelar. Palinologicamente, estas duas espécies aproximam-se de $P$. organensis pela maioria dos caracteres utilizados na chave, diferenciando-se apenas pelo diâmetro do lúmen e, macromorfologicamente, pela corona unisseriada, ápice dos filamentos dolabriformes e ovário tomentoso encontrados nesta última espécie.

Para Milward-de-Azevedo (dados não publicados), Passiflora tricuspis possui folhas 3-fendidas, flores com filamentos externos da corona filiformes, com ápice capitado e filamentos internos filiformes com ápice 2-3-lobado. Já $P$. vespertilio tem folhas obtriangulares a cuneiformes, flores com filamentos externos da corona liguliformes, unidos por membrana e com ápice capitado, e filamentos internos capilariformes. Palinologicamente, P. cervii, se aproxima, na chave polínica, destas duas espécies pela maioria das 
características, afastando-se apenas pela forma do grão de pólen, mas, macromorfologicamente, se distingue pelas folhas urniformes, flores com ápice dos filamentos da corona dilatado-achatado e ovário pubescente e híspido e pelos frutos ovados. Passiflora saxicola apresenta folhas com lobos oblongos e ápice arredondado, flores com filamentos externos da corona liguliformes e ápice capitado e ovário glabro, enquanto $P$. transversalis distingue-se pelas folhas com lobos lanceolados e ápice agudo, flores com filamentos externos da corona filiformes unidos por membrana e ápice agudo e ovário pubescente. Aproximam-se de P. pardifolia pela maioria das características polínicas, afastando-se apenas pela forma do grão de pólen, mas esta se distingue pelas flores com pétalas de ápice truncado-apiculado e filamentos da série externa da corona liguliformes.

Desse modo, o presente estudo mostra a importância que a morfologia dos grãos de pólen representa para a taxonomia do subgênero Decaloba, podendo-se depreender a relevância que esse tipo de estudo também representará para a taxonomia de outras espécies de Passiflora e para a sistemática do gênero, possibilitando uma reavaliação das circunscrições e do rearranjo de categorias infra-genéricas atualmente estabelecidas e, conseqüentemente, um melhor entendimento das linhagens filogenéticas reconhecidas.

\section{Agradecimentos}

Ao CNPq pelas bolsas concedidas aos autores. À Faperj e ao CNPq pelos auxílios liberados ao laboratório de Palinologia, Museu Nacional/ UFRJ. Ao Laboratório de Ultraestrutura Celular, do Instituto de Biofísica da Universidade Federal do Rio de Janeiro (UFRJ), na pessoa da técnica de microscopia eletrônica de varredura, Noêmia Rodrigues Gonçalves. Aos herbários pelo empréstimo do material botânico.

\section{Referências bibliográficas}

Araújo, R.C.M. \& Santos, F.A.R. 2004. Palinologia de Espécies do Gênero Passiflora L (Passifloraceae) da Chapada Diamantinaa, Bahia, Brasil. Sitientibus Série Ciências Biológicas 4(1/2): 37-42.
Barrios, L.; Caetano, C.M.; Cardoso, C.I.; Eeckenbrugge, G.C.; Arroyave, J.A. \& Olaya, C.A. 2005. Caracterización del polen de especies de los gêneros Passiflora y Dilkea. Acta Agronomica 54 (3): 19-23.

Barth, O.M. \& Melhen, T.S. 1988. Glossário ilustrado de palinologia. Campinas, Ed. UNICAMP.

Erdtman, G. 1960. The acetolysis method. A revised description. Svensk Botanisk Tidskrift 39: 561-564.

Feuillet, C. \& MacDougal, J. 2003. [2004]. A new infrageneric classification of Passiflora L. (Passifloraceae). Passiflora: The journal \& Newsletter of Passiflora Society International 13(2): 34-38.

García, M.T.A.; Galati, B.G. \& Anton, A.M. 2002. Microsporogenesis, microgametogenesis and pollen morphology of Passiflora spp. (Passifloraceae). Botanical Journal of the Linnean Society 139: 383-394.

Holmgren, P.K., Keuken, W. \& Schofield, E.K. 1990. Index herbariorum, Part 1: The Herbaria of the World. $8^{\text {th }}$. ed., New York, New York Botanical Garden.

Huynh, K.L. 1972. Étude de lárrangement du pollen dans la tétrade chez les angiospermes sur la base de données cytologiques. IV. Le genre Passiflora. Pollen et Spores 14(1): 51-60.

Killip, E.P. 1938. The American species of Passifloraceae. Publication Field Museum of Natural History - Botanical Series 19 (1-2): 1-613.

MacDougal, J. 1994. Revision of Passiflora subgenus Decaloba section Pseudodysosmia (Passifloraceae). St. Louis, Systematic Botany Monographs, v. 41.

Milward de Azevedo, M.A.; Gonçalves-Esteves, V. \& Baumgratz, J.F.A. 2004. Palinotaxonomia das espécies de Passiflora L. subg. Decaloba (DC.) Rchb. (Passifloraceae) no Sudeste do Brasil. Revista Brasileira de Botânica 27(4): 655-665.

Milward de Azevedo, M.A. 2008. Three new species of Passiflora subgenus Decaloba (Passifloraceae) from Brazil. Brittonia 60(4): 310

Presting, D. 1965. Zur Morfhologie der pollenkörner der Passifloraceen. Pollen et Spores 7: 193-247.

Punt, W. Blackmore, S.; Nilsson, S. \& Le Thomas, A. 2007. Glossary of pollen and spore terminology. Review of Paleobotany and Palynology 143: 1-81.

Roubik, D.W. \& Moreno, J.E.P. 1991. Pollen and Spores of Barro Colorado Island. St. Louis, Monographs in Systematic Botany, v. 36.

Salgado-Labouriau, M.L. 1973. Contribuição à palinologia dos cerrados. Rio de Janeiro, Academia Brasileira de Ciências.

Spirlet, M.-L. 1965. Utilisation taxonomique des grains de pollen de Passifloracées. Pollen et Spores 7(2): 249-301.

Ulmer, T. \& MacDougal, J. M. 2004. Passiflora: Passiflowers of the world. Cambridge, Timber Press. 